CIC. Cuadernos de Información y Comunicación

ISSN: $1135-7791$

http://dx.doi.org/10.5209/CIYC.60688

\title{
Las distintas concepciones del espacio en la teoría de la narración audiovisual
}

Julia Sabina Gutiérrez ${ }^{1}$

Recibido: 10 de enero de 2018 / Aceptado: 15 de febrero de 2018

Resumen. El espacio, que ha sido objeto de estudio por los semiólogos más prestigiosos, está mereciendo una atención especial en la teoría de la narración audiovisual.

Este trabajo, con los referentes de investigadores, como Gardies, Maras, François Jost...así como de cineastas como Eric Rohmer, aborda las diversas perspectivas desde las que ha sido estudiado, lo pone en relación con el tiempo y compara su tratamiento en el cine con el que se le otorga al espacio en el relato literario y en la pintura.

Palabras clave: Espacio, Imagen, Narración audiovisual, cinema.

[en] The different conceptions of space in the theory of audiovisual narrative

Abstract. The space, which has been the object of study by the most prestigious semiologists, deserves special attention in the theory of audiovisual narration.

This work, with the references of researchers, such as Gardies, Maras, François Jost ... as well as filmmakers like Eric Rohmer, addresses the diverse perspectives from which it has been studied, puts it in relation with time and compares its treatment in the cinema with to literary story and the painting. Keywords: Space, Image, Film Narration, cinema.

Sumario. Bibliografía.

Cómo citar: Sabina Gutiérrez, J. (2018). Las distintas concepciones del espacio en la teoría de la narración audiovisual, en CIC. Cuadernos de Información y Comunicación 23, 215-225.

Desde que los hermanos Lumière inventaron el cinematógrafo, artistas y creadores son conscientes del nacimiento de una nueva forma de expresión y se interrogan sobre cómo conseguir explotar al máximo sus posibilidades. Durante años las cuestiones relativas al montaje, a la profundidad de campo, al fuera de campo... han sido objeto de numerosos debates.

El espacio, concebido como por Platón en el Timeo como "receptáculo"-término que también utilizará Eric Rohmer-y analizado por Aristóteles en las conexiones de

UCM Madrid.

nasdrivia@gmail.com 
los lugares con la mimesis, ha sido objeto de estudio por los filósofos y científicos de todas las épocas.

En la narrativa audiovisual se ha concebido desde dos perspectivas fundamentales: la geográfica y la plástica. La primera consiste en el análisis del mundo de la representación fílmica del espacio, como es el estudio de una ciudad o de la geografía de un territorio de un género cinematográfico en concreto como sería el Western. La concepción plástica está ligada al medio cinematográfico en sí mismo y analiza prioritariamente la composición plástica de la imagen articulada sobre el montaje (Gardies, 1993: 11)

El espacio es el que determina ya la lectura "visual del guion", y el que sitúa la realización de una película en un continuum (Maras, 2009: 109).

Todo teórico que analiza el relato cinematográfico se termina planteando la cuestión siguiente: ¿El relato audiovisual se construye en el espacio o en el tiempo? $\mathrm{Su}$ respuesta a esta pregunta condicionará el resto de los argumentos.

Jorge Luis Borges decía en sus ensayos sobre la filosofía y literatura fantástica que el espacio no existe porque este es una de las modalidades del tiempo. Jacques Aumont subraya estas palabras del escritor argentino para hablar de la obra cinematográfica. Según Aumont, al contrario de lo sostenido por Borges en la obra cinematográfica: "il est facile de voir que les formes temporelles de l'image narrative n'existent pas en dehors de l'espace, d'un espace global où se joue la représentation $^{2} \gg$ (Aumont, 1995: 136). Ello se debe a que el film, aunque está fragmentado, es reestructurado por el espectador. El prestigioso investigador del cine, que en otras obras reclamaba para la pintura el derecho de ser tratada como un arte del tiempo, mantiene una posición contraria para el arte audiovisual: "Il s'agit, tout simplement, maintenant, de prendre le cinéma comme un art de l'espace"3. (Aumont, 1995: 137)

Revisando las tesis de otros investigadores sobre la temporalidad o espacialidad del relato audiovisual, se comprueba que las posiciones distan de ser unánimes. Para Christian Metz, el texto fílmico moviliza a la vez el espacio y el tiempo y afirma que el componente espacial está siempre presente puesto que el relato fílmico se realiza a través de la imagen. "Au cinéma, en effet, l'espace est toujours présent ; il l'est même dans le récit, puisque le récit filmique se réalise par l'image"4 (Metz, 1981 : 27).

No obstante, en las teorías de Christian Metz, el espacio termina ejerciendo una función de segundo orden, y nos invita a preguntarnos de qué manera reconocemos un relato cinematográfico (Metz, 1981: 26). En el relato audiovisual, explica el ilustre semiólogo, al contrario que en el mundo "real", existe un principio y un fin y esto lo delimita del resto del mundo. De esta manera, si un relato tiene un principio y un fin es porque se trata de una secuencia temporal, en la que conviven dos temporalidades diferentes: por un lado, el tiempo de la historia contada y por otro el tiempo del discurso (Metz, 1981: 27). Esta duplicidad de temporalidades puede provocar distorsiones aparentes, al poder relatar tres años de vida de un personaje en dos frases de una novela o en, el caso del relato audiovisual, en algunos planos de montaje.

\footnotetext{
2 Es fácil ver que las formas temporales de la imagen narrativa no existen fuera del espacio, de un espacio global en el que se lleva a cabo la representación.

Se trata simplemente de considerar el cine como un arte del espacio.

$4 \quad$ En efecto, en el cine, el espacio está siempre presente; lo está incluso en el relato porque el relato fílmico se realiza a través de la imagen.
} 
Ello posibilita que puedan distinguirse tres posibilidades de relación entre el espacio y el tiempo en el relato audiovisual:

Un plano solo e inmóvil de un desierto es una imagen.

Significado-espacio $\rightarrow$ Significante-espacio

Varios planos parciales y sucesivos de este desierto constituyen una descripción.

Significado-espacio $\rightarrow$ Significante-tiempo

Varios planos sucesivos de una caravana en marcha en un desierto forman una narración.

Significado-tiempo $\rightarrow$ Significante-tiempo

Estos ejemplos ponen de manifiesto que el relato es, entre otras cosas, un sistema de transformaciones temporales (Metz, 1981: 27), por lo que terminaría convirtiéndose en una continuación más o menos cronológica de acontecimientos.

Sin embargo, esta definición temporal del relato contrasta con lo que denomina estatus híbrido y molesto de la descripción: "La description apparaît à la fois comme l'opposé de la narration et comme une des grandes figures ou un des grands moments de la narration"5 (Metz, 1981: 28).

Estos argumentos adquieren una mayor complejidad si se añade un tercer elemento: la imagen. La narración y la descripción se oponen conjuntamente a la imagen porque el significado de la narración está temporalizado, mientras que el significado de la imagen es instantáneo (Metz, 1981: 28). De este modo observamos cómo el parámetro "imagen" plantea problemas en el análisis teórico expuesto por Metz.

Seymour Chatman recoge estas ideas, con una nueva explicación y desarrollo del carácter espacial de la imagen cinematográfica, profundizando en el análisis comparativo de la historia y del discurso del relato cinematográfico y literario (Chatman, 1990). Y, al igual que considera que existe un tiempo de la historia y un tiempo del discurso, distingue entre un espacio de la historia y un espacio del discurso:

As the dimension of story-events is time, that of story existence is space. As we distinguish story-time from discourse-time, we must distinguish story-space from discourse-space. The distinction emerges most clearly in visual narratives. In films explicit story-space is the segment of the world actually shown on the screen; implied story-space is everything off-screen to us but visible to the characters, or within earshot, or alluded to by the action. (Chatman,1990: 96)

Para estudiar el story-space (el espacio de la historia) deben tenerse en cuenta unos parámetros espaciales como serían la escala o tamaño, el contorno, textura y densidad, la posición, el tipo de iluminación y color, la resolución (Chatman, 1990: 97). Aunque Chatman termina afirmando que la diferencia entre el espacio del discurso y el espacio de la historia no es tan clara como cuando analizamos el tiempo: "The borders between story-space and discourse-space are not easy to establish as those between story-time and discourse-time" (Chatman, 1990: 98). Lo que obedece, según él, a que, al contrario que en una secuencia temporal, la disposición física de

La descripción aparece a la vez como lo opuesto a la narración y como una de las grandes figuras o de los grandes momentos de la narración. 
los elementos no tiene una lógica natural en el mundo real. Mientras que el tiempo pasa para todos en la misma dirección, la disposición espacial depende de la situación de los objetos, del sujeto..., y su posición en el espacio es mucho menos racional: "Life offers no predertemined rationale for these placements. They are all choices, that is, products of the art of the director" (Chatman, 1990: 98)

De esta manera, Chatman revisa la cuestión anteriormente expuesta por Metz: el papel de la descripción en el relato cinematográfico, y argumenta a este respecto que el cine no puede describir en un sentido estricto, es decir, no puede detener la acción, ni incluso en el caso de las imágenes congeladas. El cine puede únicamente "ser visto" (It can only "let be seen"), y existen algunas argucias para poder "ser visto" de un modo más descriptivo como serían los close-ups o ciertos movimientos de cámara, pero a esto no lo podríamos considerar como descripciones en un sentido estricto (Chatman, 1990: 106).

Estos argumentos son debatidos por algunos críticos, que se plantean si se está partiendo de una concepción errónea del espacio. Es la hipótesis que formula Julio Sánchez Andrada en su artículo El espacio: un problema pendiente en la teoría narrativa del discurso audiovisual (Sánchez Andrada, 2009: 281-291). Para este investigador la teoría del relato todavía tiene que aportar una explicación adecuada del espacio en la representación audiovisual por dos razones principales: por la influencia que ha tenido y sigue teniendo la lingüística en la teoría cinematográfica y por una concepción del espacio influida por la ciencia matemática:

La causa, a mi entender, más profunda tiene que ver con el concepto de espacio que manejan la mayoría de los investigadores del relato, estructuralistas o no, y que parece derivada de las teorías científico-filosóficas de Clarke y Newton. Bajo esa perspectiva el espacio queda más allá de toda acción y, al mismo tiempo, ajeno a los seres que lo habitan: una concepción difícilmente sostenible no sólo desde la física moderna sino desde los actuales conocimientos de la fisiología y de la psicología (Sánchez Andrada, 2009:228)

En esta revisión, y a la vez en una nueva interpretación del espacio en el relato cinematográfico, destacan los trabajos de André Gardies, François Jost y André Gaudrealut, así como las investigaciones del Groupe Mu o Lakoff y Johnson en el campo de las metáforas orientacionales.

André Gaudrealt y François Jost imprimen un giro a esta concepción del espacio como realidad de segundo orden, dedicando un capítulo entero al estudio de este elemento en Le récit cinématographique.

La unidad de base en el relato cinematográfico, según los dos teóricos, es la imagen, que es la que otorga al relato audiovisual la singularidad de poder ver al mismo tiempo las acciones y su contexto:

L'unité de base du récit cinématographique, l'image, est un signifiant éminemment spatial, de sorte que, au contraire de bien d'autres véhicules narratifs, le cinéma présente toujours, on le verra, à la fois les actions qui font le récit et leur contexte d'occurrence' (Gaudrealt, Jost, 1990 : 79).

\footnotetext{
6 La unidad de base del relato cinematográfico, la imagen, es un significante eminentemente espacial, al contrario de muchos otros vehículos narrativos, el cine presenta todavía, lo veremos, al mismo tiempo las acciones que hacen el relato y su contexto de ocurrencia.
} 
De este modo, la imagen deja de ser un elemento molesto en el análisis del relato audiovisual y se convierte en el factor que le otorga singularidad en contraste con el relato literario. De hecho, llegan a afirmar que el carácter icónico del significante fílmico va a imponer al espacio una cierta primacía sobre el tiempo (Gaudrealt, Jost, 1990: 79).

¿No es ésta la premisa tan repetida en los manuales de guiones: Think in images (Piensa en imágenes)? Al contrario que en el relato lingüístico, al crear una escena audiovisual se debe pensar en lo que ocurre arriba, abajo, a los márgenes o en la profundidad del cuadro. Es decir, para construir una escena hay que tener en cuenta los acontecimientos que ocurren al mismo tiempo, en un mismo sitio y no en acontecimientos que ocurren unos detrás de otros, siguiendo una disposición lineal como en el discurso literario.

Varios son los guionistas que hablan del componente espacial como del elemento que distingue su trabajo de la narrativa literaria. Por ejemplo, Jean-Claude Carrière explica cómo incorporaba dibujos cuando trabajaba con Jacques Tati y Pierre Étaix, siguiendo la tradición de Méliès en la que se otorga prioridad a la representación espacial del relato:

Dans les films de Jacques Tati y de Pierre Étaix, tout est préparé de manière très précise, avec ces croquis qui expliquent tous les effets comiques (...) Ceci a, évidemment, une relation forte avec le montage, et fusionne l'écriture et l'harmonisation dans des activités inséparables ${ }^{7}$. (Carrière, 1996: 25)

A su vez, investigadores, como François Jost y André Gaudreault, añaden el elemento del fotograma al tiempo, es decir, consideran el tiempo cinematográfico como una temporalidad que se apoya en el espacio:

Et, puisque le photogramme vient avant la succession de photogrammes, la temporalité au cinéma doit effectivement s'appuyer sur l'espace pour arriver à s'inscrire au sein du récit. Le temps n'y est en devenir que lorsque l'on opère le passage entre un premier photogramme (qui est déjà espace) et un deuxième (qui est, lui aussi, déjà espace) ${ }^{8}$ (Gaudrealt, Jost, 1990 : 79).

Por estas razones, argumentan que la construcción de las escenas se produce en simultaneidad y no en su sucesión.

Sin embargo, la imagen no es el espacio, como explica acertadamente Jacques Aumont, para quien la existencia del espacio en las imágenes pictóricas o fílmicas tiene que ver con el espacio en tanto que es "visto", y las cosas empiezan a ser más simples y menos "naturales" porque el espacio no es aquí una percepción como lo son el movimiento o la luz; el espacio no es visto directamente sino que es construido a partir de concepciones visuales, así como de concepciones kinésicas y táctiles. Jacques Aumont remite entonces, como ya han hecho anteriores investigadores, a

7 En las películas de Jacques Tati y Pierre Etaix, todo estaba preparado de manera muy precisa, con croquis que explicaban todos los efectos cómicos. (...) Esto tiene, evidentemente, una relación fuerte con el montaje, y fusiona la escritura y la harmonización en actividades inseparables.

8 Y, debido a que el fotograma existe antes que la sucesión de fotogramas, la temporalidad en el cine debe apoyarse sobre el espacio para inscribirse dentro del relato. El tiempo no se encuentra en devenir si no se opera el pasaje entre un primer fotograma (que ya es espacio) y un segundo (que también es espacio). 
conceptos como la perspectiva artificialis de Brunelleschi y Alberti, que es una invención artificial y no una ley natural (Aumont, 1995: 139).

No obstante, el espacio en el cine se encuentra en la misma contradicción perceptiva que la pintura, ya que representa un espacio tridimensional en un espacio realmente bidimensional, el del lienzo o la pantalla (Aumont, 1995: 140). Se constituye en el cine una “double réalité, puisque l'oeil perçoit en même temps l'espace plat de la surface de la toile et la vue partielle sur un fragment d'espace "en profondeur", produit entre autres par l'emploi de la perspective. Double réalité, puisque l'un et l'autre de ces espaces sont réellement perçus, et jusqu'à un certain point, perçus comme reels"9 (Aumont, $1995: 140$ )

En relación con el problema de la bidimensionalidad o tridimensionalidad de la imagen cinematográfica, Steven Heath añade que el cine no es ni lo uno ni no lo otro, y parte de la noción del cine como something in between. Esta noción es para él fundamental en el estudio del espacio fílmico ya que explicaría la impresión de realidad, debido a que el cine utiliza las imágenes producidas en fotografía para reproducir movimiento:

The result is characterized as "neither absolutely twodimensional nor absolutely three-dimensional, but something between." The "something between" is the habitual response to the famous "impresion of reality" in cinema and it is this impression, this reality that are of concern here in their implications for a consideration of space in film (Heath, 1981: 27).

Heath se sitúa, por tanto, en la misma línea que André Gardies, en la que concibe el espacio no como un aspecto físico de un medio en tres dimensiones donde se ordenan los objetos, sino desde la perspectiva de una abstracción de tipo estructural mayor (Gardies, 1993: 70).

Esta cuestión lleva a Aumont a preguntarse qué ha heredado el cine de otras artes como el teatro y la pintura, artes en las que también se representa y construye el espacio:

Est-ce à dire que le cinéma a deux façon de représenter le réel, l'une qui viendrait du théâtre, l'autre de la photographie? Cette thèse (...) est un peu brutale, et je l'explicite seulement pour faire ressortir ce qui manque massivement dans la conception de la représentation filmique comme vue : la mise en scène ${ }^{10}$ (Aumont, 1995: 154).

\section{Desarrolla ampliamente estas interesantes cuestiones y termina afirmando}

Dernier des arts, dernier lieu où se joue encore quelque chose d'une dialectique entre croyance, imagination et perception diffuse du matériau: dernière relève du

\footnotetext{
9 Dobre realidad porque el ojo percibe al mismo tiempo el espacio pleno de la superficie del lienzo y la vista parcial sobre un fragmento de espacio «en profundidad», producido entre otros por el empleo de la perspectiva. Doble realidad, porque uno y otro espacios son realmente percibidos, y hasta cierto punto, percibidos como reales.»

10 ¿Puede ser que el cine tenga dos formas de representar la realidad, una que viene del teatro, otra de la fotografía? Esta tesis (...) es un poco brutal, y lo explico solo para hacer resurgir lo que falta masivamente en la concepción de la representación fílmica como vista: la puesta en escena.
} 
théâtre dans la peinture. Le cinéma, ou le dernier espace imaginable ${ }^{11}$ (Aumont, 1995: 164)

En esta misma línea se sitúa Eric Rohmer cuando se refiere a lo que el cine le debe a la pintura y a la cultura pictórica de los creadores ${ }^{12}$. Nos recuerda que los que inspiraron las primeras películas del cine fueron los caricaturistas y sus viñetas humorísticas. L'Arroser arrosé antes de ser rodado por los hermanos Lumière era "une histoire sans paroles" dibujada por Herman Vogel y por Christophe.

Según él, los cineastas conocían perfectamente los cómics de la época:

Sont légion les cineastes qui ont fait preuve d'invention dans ce domaine, nous proposant leurs formes, leus types, leur mise en page, presque leur trait, leur touche. Citons par exemple Hitchcock ou Fritz Lang et, pourquoi pas, le cinéma américain dans son ensemble : thriller, western, burlesque, musical etc... ${ }^{13}$ (Rohmer, 1977: 16)

Estas cuestiones invitan a preguntarnos cuál pudo ser la influencia del teatro y de la pintura en la construcción espacial de las historias. El debate parece pertinente porque multitud de realizadores como Tim Burton, David Lynch, Peter Greenaway, Pier Paolo Pasolini, Gus Van Sant... son importantes artistas plásticos.

Por su parte, André Gardies, en su obra L'Espace au cinema, analiza distintos tipos de espacio en el seno de una película. Considera fundamental el espacio diegético, que es aquel que construimos en nuestra mente uniendo unos fragmentos de espacio con otros e imaginando lo que no hemos visto. Gardies niega que podamos tener una mirada nueva y limpia hacia lo que miramos, no porque todo haya sido dicho o leído, sino porque cada nuevo texto nace en un mundo cultural constituido en cada espectador (Gardies, 1993: 68).

Para iniciar su análisis, Gardies se centra en la realidad y especificidad de los lugares (una montaña, una ciudad o una casa, por ejemplo). Y, al igual que Ferdinand de Saussure, distingue entre la lengua y el habla para explicar qué es el lugar en el espacio. El lugar sería el portador de propiedades espaciales; "el lugar" es la palabra del espacio-lengua ya que viene cargado de sentido dentro de nuestros parámetros sociales y culturales (Gardies, 1993: 75). Buenos ejemplos de ello serían los spaguetis western que apelan a un lugar en el que no fueron realizados. El lugar donde se desarrolla una historia juega un papel fundamental en nuestras expectativas de lo que nos esperamos del relato. De este modo presenta un paralelismo entre los lugares y la clasificación de personajes realizada por P. Hamon (Gardies, 1993: 76). Esta clasificación resulta de gran utilidad para analizar las escenas (siendo la escena la uni-

11 Último arte, último lugar donde se juega todavía algo como una dialéctica entre creencia, imaginación y percepción difusa del material: último relevo del teatro en la pintura. El cine, o el último espacio imaginable.

12 Eric Rohmer realizó una tesis doctoral dedicada al espacio en el Faust de Murnau. Distingue tres tipos diferentes de espacio: el espacio pictórico, el espacio arquitectural y el espacio fílmico. Rohmer explica que estos tres espacios corresponden a tres modos de percepción de la materia fílmica por el espectador. Además, estos espacios son resultado de tres procesos diferentes de la reflexión del cineasta y de tres etapas de su trabajo donde utiliza, en cada etapa, técnicas diferentes (Rohmer, 1977: 11)

13 Muchos son los cineastas que han hecho invenciones en este campo, proponiéndonos en sus formas, en sus tipografías, en su puesta en la página, prácticamente su trazo, su toque. Citemos, por ejemplo, a Hitchcock o Fritz Lang y, por qué no, al cine americano en su conjunto: thriller, western, burlesque, musical. etc... 
dad mínima del guion). No olvidemos que en un guion no se distinguen las secuencias sino las escenas. Las escenas son la unidad narrativa mínima y ocurren en un tiempo y en un lugar específicos. Cada vez que hay un cambio de lugar se inicia una nueva escena.

Rohmer insiste igualmente en la importancia del "lugar" en el análisis del espacio de una película. El cineasta y ensayista estudia la arquitectura del espacio del film no desde el punto de vista de la creación de las formas sino desde el de su función. En su ensayo recorre uno a uno los decorados del film Le derniere des hommes (una puerta giratoria, un baño, la fachada de un edificio) y examina su función a través de los sentimientos que nos transmiten: inquietud, funcionalidad, inestabilidad:

Tous ces lieux ne se présentent pas seulement comme le cadre de l'action, son réceptacle. Ils pèsent sur les attitudes des personnages, infléchissent leur jeu, dictent leurs déplacements ${ }^{14}$ (Rohmer, 1977: 58).

Rohmer realiza un dibujo de la inferencia de uno de los lugares de El Fausto de Murnau donde un mismo decorado, un despacho, tiene distintas funciones en distintas escenas.

En el relato fílmico el espacio diegético está habitado por esa población singular que son los lugares. Este conjunto de lugares de un relato constituye una rica cantera de valores que serán reutilizados en la actividad narrativa (Gardies, 1993: 86).

Para Gardies, el paso de sintagma a sintagma en el seno de una película permite crear una aprehensión cognitiva del espacio propio de la narración que se está desarrollando, lo que denomina espacio narrativo. A medida que avanza el relato, el espectador elabora un modelo abstracto de la organización del conjunto gracias a la cual se asegura por un lado la coherencia y, por otro, se percibe el juego relacional de los distintos componentes espaciales.

Este espacio narrativo, sin embargo, no tiene sentido si no está habitado por un personaje. El espacio es concebido como un trabajo de intercambio constante entre el espacio y el sujeto. Es la estrecha relación entre el personaje y el espacio la que funda la narración de una película. ¿No es una alegoría perfecta Manhattan del personaje de Woody Allen?

En un primer momento, el acto inaugural de un relato consiste en la puesta en relación dinámica entre un personaje y un espacio. Todo relato cuenta de manera explícita o alusiva la historia de un hombre y sus relaciones con el espacio ya que el personaje no puede transformarse ni llegar a ser otro sin el rol activo del espacio. Esto quiere decir que, dentro de la perspectiva semiótica narrativa, el personaje antes de actuar debe estar constituido como tal y adquirir ciertas cualidades fundamentales. El sujeto antes de poder actuar, debe dotarse de un "ser" y de un "hacer".

En este sentido, el desplazamiento es la condición necesaria para el encuentro de fuerzas agitadoras del relato. No obstante, su estatus puede estar dotado de complejidad ya que puede ser que el desplazamiento sea la prueba en sí misma, como es el caso de las road-movies, y puede desbordar su rol principal y tener en sí mismo una función catalizadora. Gardies distingue, a este respecto, tres tipos de desplazamiento:

14 Todos estos lugares no se presentan únicamente como el marco de la acción, su receptáculo. Pesan sobre las actitudes de los personajes, influyen en su forma de actuar, dictan sus desplazamientos. 
- El trayecto: paso de un punto a otro. Su valor catalizador (término recogido de Roland Barthes) es preponderante (Gardies, 1993: 154)

- El recorrido: elemento esencial en el relato del vagabundeo. Obstáculos y dificultades de todo orden pueden ocurrir en función cardinal.

- El itinerario: por su valor globalizador abarca el conjunto de la historia, al mismo tiempo que le dota de sentido porque se persigue un fin; sobre el modelo del itinerario se organiza fundamentalmente el relato de la búsqueda.

Argumenta que el espacio es "el otro" que comunica con el sujeto, y con el que, -sobre la base del intercambio-, se producen transformaciones que aseguran la dinámica narrativa: “L'Espace n'est plus seulement ce décor sur le devant duquel s'enlève l'action, il est l'un des acteurs évoluant sur la scène narrative" 15 (Gardies, 1993: 161)

Sin embargo, en el cine lo que se muestra y el punto de vista desde el que se muestra están indisolublemente unidos y el estudio del espacio y la imagen no pueden desvincularse del punto de vista. François Jost y André Gaudreault desarrollan este asunto con gran sagacidad. A esta capacidad de distanciarse y de situarse en el espacio de la cámara lo denominan «pluripuntualidad»:

La pluriponctualité du cinéma peut, en termes narratifs, être considérée comme une sorte de "langage", un langage d'ordre à la fois spatial et temporel. (...) L'ubiquité de la caméra est un paramètre qui dote la pluriponctualité du coefficient de la distance. Avec la pluriponctualité surgit donc une certaine forme de diversité spatiale qui pose pour le spectateur le problème de la relation à établir entre deux espaces (et, éventuellement, deux temps) montrés par deux plans se suivant immédiatement ${ }^{16}$ (Gaudreault, Jost, 1990:90).

Para ellos cada raccord tiene un nivel de significación espacial e identifican cuatro tipos diferentes de relaciones espaciales.

- La identidad espacial: si nos encontramos frente a un solo y mismo espacio.

- La alteridad espacial: cuando nos encontramos con diferentes espacios. Esta alteridad espacial puede ser de dos tipos.

- Contigua: Cuando las informaciones contenidas en los dos planos llevan al espectador a inferir una continuidad directa (y virtualmente sin fallo) entre dos segmentos. Un buen ejemplo sería el plano-contraplano (Gaudreault, Jost, 1990:93)

- Separada, en cuya explicación se recurre a dos términos empleados en anatomía y psicología de la percepción, que son la separación "próxima" y la separación "distante" (Gaudreault, Jost, 1990:95).

15 El espacio no es únicamente el decorado sobre el que se desarrolla la acción, es otro de los actores que evoluciona sobre la escena narrativa.

16 La pluripuntualidad del cine puede, en términos narrativos, ser considerada como una especie de «lenguaje», un lenguaje al mismo tiempo espacial y temporal. (...) La ubicuidad de la cámara es un parámetro que da la pluripuntualidad del coeficiente de la distancia.Con la pluripuntualidad surge por lo tanto una cierta forma de diversidad espacial que plantea al espectador el problema de la relación a establecer entre dos espacios (y, eventualmente, dos tiempos) mostrados por dos planos que se siguen inmediatamente. 
Se produce la separación próxima cuando dos segmentos espaciales son leídos como relativamente separados, pero próximos (Gaudreault, Jost, 1990:95). No se debe confundir con el caso de amplificar una imagen o un sonido como sería la imagen de una lupa. Existe separación "próxima" cuando la cámara nos hace traspasar dos espacios adyacentes franqueados por un muro sin que ningún personaje nos lleve de uno a otro.

En la separación distante, este tipo de raccord espacial se distingue de los anteriores por la pregnancia de su equivalente lingüístico. Es considerado como distante todo lo que en un segundo plano es rechazado por lo representado en el plano precedente.

A través de estas articulaciones, el cineasta traslada a la pantalla lo que aparece escrito en el guion cinematográfico. Aunque se ha subrayado la idea de un espacio que se construye en la mente uniendo fragmentos de imagen con otros, no debemos olvidar un elemento fundamental en la construcción espacial, que es el sonido.

La cámara en el cine tiene potencialmente el poder de la ubicuidad. Ya hemos visto cómo el paso de unos planos a otros puede verse afectado por los anteriores. Todo esto nos conduce a plantearnos un problema más amplio: quién nos cuenta la historia y cómo nos la cuenta. Jost y Gaudreault se plantean este problema fundamental del punto de vista y cómo afecta a la representación espacial y a la capacidad de la cámara de poder estar en todas partes.

Todorov (1966) ya distinguía los siguientes puntos de vista atendiendo fundamentalmente al relato literario:

- El narrador sabe más que el personaje: Narrador $>$ Personaje.

- El narrador sabe lo mismo que el personaje: Narrador $=$ Personaje.

- El narrador dice menos que lo que sabe el personaje: Narrador < Personaje (Gaudreault, Jost, 1990: 128).

Sin embargo, en el relato audiovisual resulta difícil aplicar esta clasificación. Si hasta ahora, denominaciones como campo, punto de vista o visión venían siendo empleadas en los estudios de la narrativa audiovisual, Jost y Gaudreault formulan una terminología más específica y proponen utilizar el término focalización, empleado por Genette (1972).

Los autores plantean tres tipos diferentes de focalización, atendiendo al punto de vista: Relato no focalizado o focalización cero: cuando el narrador es "omnisciente", es decir, el narrador dice más que lo que saben los personajes.

- Relato con focalización interna: cuando el relato muestra los acontecimientos como si estuviesen filtrados por la consciencia de un solo personaje. Este tipo de narración puede ser de dos modalidades: variable, cuando el personaje que narra cambia a lo largo del relato, y múltiple, cuando el mismo acontecimiento puede ser evocado varias veces según el punto de vista de los personajes.

- Relato con focalización externa: cuando el espectador no puede conocer los pensamientos o sentimientos del héroe (Gaudreault, Jost, 1990:128-129)

Si los autores recurren con frecuencia a términos literarios, sin embargo, al definir la focalización en el cine, los investigadores aclaran que se trata de una denominación metafórica. Prefieren el término de focalización para establecer una diferencia 
entre lo que vemos y lo que escuchamos, o lo que ellos denominan: la ocularización y la auricularización.

Lo que se deriva de estos análisis es que las relaciones espaciales no pueden explicarse sin la referencia al contexto narrativo. Sin embargo, y aunque en el cine exista siempre una narratividad, frente a la morfología del relato literario, estudiado por Propp (1998), por Todorov (1966) y por otros autores, en el que su representación es esencialmente simbólica, en el relato audiovisual del cine y de la televisión uno de sus rasgos fundamentales es la mostración, la ostensión, que es considerada por Elam (1980) la forma de semiosis más elemental.

Y así como la pintura elabora un sistema de representación, el cine elabora un espacio imaginario, un espacio narrativo, dice Stephen Heath (1981), que hace posible que pueda relatarse una historia.

\section{Bibliografía}

Aumont, Jacques (1995). L'oeil interminable, Paris, Nouvelles Éditions Séguier.

- (2002). Les théories des cinéastes, Paris, Nathan Cinéma. Chatman, Seymour (1990). Coming to terms. The retoric of Narrative in Fiction and Film, New York Cornell University Press.

Elam, Keir (1980). The Semiotics of Theatre and Drama, Londres, Meteuen. Gardies, André (1993). L'espace au cinema, Paris, Méridiens Klincksieck.

- (1999). Décrire à l'écran, Paris, Méridiens Klincksieck.

Gaudreault, André- Jost, François (1990). Le récit cinématographique. Cinéma et récit II, Paris, Nathan.

Genette, Gérard (1972). Figures III, Paris, Seuil. Heath, Stephen (1981). Questions of Cinema, USA, Indiana University Press.

Maras, Steven (2009). Screenwriting: History, Theory and Practice, London, Wallflower Press.

Metz, Christian (1971). Langage et cinéma Paris. Librairie Larousse.

- (1981). Essais sur la signification au cinema, Tome II, Paris, Éditions Klincksieck.

Propp, Vladimir (1998). Morfología del cuento, Madrid, Ediciones Akal.

Rohmer, Eric (1977). L'organisation de l'espace dans le «Faust» de Murnau. Paris, Union générale d'éditions

Sánchez Andrada, Julio (2009). "El espacio: un problema pendiente en la teoría narrativa del discurso audiovisual", Icono 14, $\mathrm{N}^{\circ} 12$, pp. 281-291.

Todorov, Tzvetan, "Les catégories du récit littéraire", en Communications n 8, Paris, Seuil, 1966. 